\title{
Augmenting Osteointegration of Proximal Femoral Endoprosthesis Using Porous Titanium Bridging Endosteal Collars: preliminary medium-term results
}

\section{Raja Bhaskara Rajasekaran ( $\nabla$ rajalibra299@gmail.com )}

University of Oxford Nuffield Department of Orthopaedics Rheumatology and Musculoskeletal Sciences https://orcid.org/0000-0003-0378-7411

\section{Thomas William Hamilton}

University of Oxford Nuffield Department of Orthopaedics Rheumatology and Musculoskeletal Sciences

\section{Duncan Whitwell}

University of Oxford Nuffield Department of Orthopaedics Rheumatology and Musculoskeletal Sciences

\section{Ben Kendrick}

University of Oxford Nuffield Department of Orthopaedics Rheumatology and Musculoskeletal Sciences

\section{Adrian Taylor}

University of Oxford Nuffield Department of Orthopaedics Rheumatology and Musculoskeletal Sciences

\section{Christopher L.M.H Gibbons}

Oxford University Hospitals NHS Foundation Trust Nuffield Orthopaedic Centre

Thomas Daniel Arthur Cosker

Oxford University Hospitals NHS Foundation Trust Nuffield Orthopaedic Centre

\section{Gordon Blunn}

University of Portsmouth

\section{Research Article}

Keywords: proximal femur replacement, titanium, osteointegration, aseptic loosening, endosteal collar

Posted Date: March 8th, 2021

DOI: https://doi.org/10.21203/rs.3.rs-305829/v1

License: (ㅇ (i) This work is licensed under a Creative Commons Attribution 4.0 International License. Read Full License 


\section{Abstract \\ Background}

Aseptic loosening remains a major cause for failure of proximal femoral replacements (PFR). To reduce the incidence of aseptic loosening a PFR was developed with a selective laser sintered, porous titanium-bridging collar and endosteal component. This study reports the short-term outcomes of this implant in a consecutive series of patients.

\section{Methods}

Between October 2017 and August 2019, 24 patients, mean age 69 years (50-84) were managed using this PFE for a variety of aetiologies (10 oncological, 10 revision of aseptic loosening, 3 fracture non-union, and 1 for prior infected joint replacement). Patients were followed up at a mean of 24 months (16-34) with a clinical and radiographic assessment.

\section{Results}

Twenty-three patients were available for follow-up with one death in the early postoperative period. One patient died 18 months post-surgery due to causes unrelated to surgery, two cases of superficial infection were managed with antibiotics and two cases of deep infection managed with debridement, antibiotics, and implant retention (DAIR). At the last follow up the mean Harris Hip Score was 78 (68-86) and the mean Musculoskeletal Tumour Society Score was 20 (16-24). The radiographic assessment did not reveal any evidence of loosening with the integration of the endosteal collar observed in all cases.

\section{Conclusions}

Our medium-term results demonstrate good functional outcomes with no evidence of radiographic loosening and osteointegration of the endosteal collar in a consecutive series of patients. Further studies are required to assess the mid to longterm outcomes seen with this implant.

\section{Level of Evidence:}

Level IV - Retrospective Case Series

\section{Background:}

Proximal femur replacement (PFR) is a viable option for various aetiologies including oncology surgery, revision arthroplasty, and non-unions following fracture fixation [1-3], and for this reason, the use of this implant is increasing. Apart from the increased cost associated with the implants used, PFR surgery is also associated with an increased complication rate compared to conventional total hip arthroplasty [3, 4]. With an implant survival rate of only $73 \%$ at 5 years, failure of PFR is demanding on the patient, surgeon, and healthcare payer often leading to more extensive surgery by way of total femur replacement (TFR) or amputation in some cases [3-5]. Due to the increasing utilization of PFR in clinical practice, and devastating consequences of failure, attention has turned to improve implant survival to achieve better patient outcomes and decreased strain on the healthcare system.

Aseptic loosening remains a major cause for failure of PFR with loosening rates of up to $29 \%$ at $4-10$ years $[4,6]$ with aseptic loosening typically being associated with poor functional outcomes and increased incidence of revision surgery [7]. With the increase in the use of PFR worldwide, in part due to expanding indications for this type of implant, efforts have been aimed at developing implants with newer materials involving advanced technology which would increase prosthesis longevity [8-10]. 
Aseptic loosening has been shown, to begin with, osteolysis at the bone-prosthesis junction followed by extension along the stem, finally culminating in prosthesis loosening [8].

Histologic studies by Blunn and Wait have shown that aseptic loosening could be reduced by preserving load transfer at the prosthesis shoulder through osteointegration leading to reduced stresses around the cement mantle [11]. To reduce aseptic loosening and improve prosthesis longevity, implant designs aimed at achieving better osteointegration at the bone-prosthesis junction where they would form a 'purse string' that seals the bone interface thereby preventing migration of wear particles [8]. Finite element analysis studies have shown that better osteointegration at the bone-prosthesis junction would prevent aseptic loosening by increasing load transfer at the shoulder of the prosthesis reducing stresses at the stem /bone interface [12]. By enhancing osteointegration and thereby increasing prosthesis longevity, better functional outcomes could also be achieved with these major surgeries.

The Pantheon PFR (Adler Ortho S.p.A, Milan, Italy) was designed to improve the integration of the bone with the prosthesis. The modular system is made up of a bridging collar which is designed to sit on top of the femoral resection with an endosteal extension that is designed to achieve a press-fit within the diaphyseal bone. The novel bridging collar is a substantially porous titanium alloy (Ti6Al4V) with a pore size of 1000 microns manufactured by 3D printing using selective laser sintering of alloy powder (Fig. 1).

Due to the theoretical benefits of the porous titanium bridging collars in improving the integration of the prosthesis at the boneprosthesis junction our unit has recently started using this PFE with the aim of this study to report the clinical and radiographic outcomes of a consecutive series of patients managed with this implant.

\section{Materials And Methods:}

Between October 2017 and August 2019, 24 patients with a mean age of 69.1 years (50 - 84) were managed with the Pantheon PFR with an endosteal titanium porous bridging collar. The etiology of the cases was as follows: ten patients had resections due to oncological diagnosis, ten patients had revision joint replacement surgery following aseptic loosening, three patients had surgery for non-union of the proximal femur and one patient was a second stage revision for a previously infected hip replacement. Of the patients who had an oncological diagnosis, one patient received neoadjuvant and adjuvant chemotherapy before and after surgery. No patient received radiotherapy. The median pre-operative ASA grade was 2 (range 1 - 3). This study was performed as an audit project and all patients had consented for their radiographs and clinical details to be used in this study.

\section{Surgical technique:}

All procedures were undertaken using the posterior approach. After adequate resection of the proximal femur and reaming of the canal, endosteal reaming was performed to allow for the bridging collar to sit tightly in the femur. Facing reamers were used to facilitate the flush fitting of the prosthesis on the cut femoral surface. A trial reduction is performed, confirming the optimal implants required. For cemented implantation, the canal is washed and brushed and a cement restrictor is applied at the desired level. The femoral canal was then retrograde washed and dried with ribbon gauze. Cement was inserted using a cement gun with a third-generation technique. Attention to the cementing technique was of utmost importance to achieve good osteointegration in the bridging collar. To avoid cement being introduced into the porous section of the collar, cement was only introduced into the canal to within approximately $3 \mathrm{~cm}$ of the cut surface to allow the cement to rise under pressurization to the bottom of the collar. The collar has a non-porous end to divert any cement away from the porous surface. Twelve patients required an acetabular component. Five also required a dual mobility bearing. The decision to use a dual mobility bearing was made by the operating surgeon when they felt that there was a need for more stability due to the resection and associated soft tissue insufficiency. The remaining six patients who had good acetabular cartilage underwent bipolar-bearing replacement.

All patients had a standard physiotherapy protocol which involved either partial or full weight bearing, at the discretion of the surgeon, for 6 weeks following surgery followed by full weight-bearing thereafter for all patients. All patients received thromboprophylaxis for 5 weeks following surgery in the form of subcutaneous Dalteparin injection (5000 units s/c once a day) 
in line with NICE guidance. All patients were followed up at six weeks, twelve weeks, six months, and then 6 monthly intervals. Antero-posterior and lateral radiographs of the entire femur were taken during follow-up visits. The bone-prosthesis junction involving the collar was assessed in all radiographs in both views to identify the presence of any radiolucent lines. The evaluation was done independently by three individuals: two orthopaedic fellows and a consultant. Any gap of more than $1 \mathrm{~mm}$ observed was considered radiolucent. Any disagreement was settled by mutual agreement. Outcomes were assessed using the Musculoskeletal Tumor Society (MSTS) and Harris Hip Score (HHS) at the last follow-up.

Continuous data were analyzed with simple descriptive statistics. All patients consented to the study.

\section{Results:}

At the time of our analysis, 23 patients were available for follow-up (Table 1). One patient, a 50-year-old woman who had surgery for a failed dynamic hip screw fixation, died in the first postoperative week. Twenty-three patients with an average follow-up of 24 months (16-34) were assessed clinically and radiologically. One patient died due to pulmonary metastasis from primary cancer 18 months after surgery. During his latest follow-up, his radiographs showed a well-fixed implant with no evidence of loosening. Two patients had a superficial wound infection which settled with regular dressings and oral antibiotics. Two patients developed deep infection which required a debridement, antibiotics, and implant retention (DAIR) procedure with vancomycin mixed Stimulan (Biocomposites, UK) - an absorbable calcium sulfate - in combination with systemic antibiotics. All of them recovered well with no evidence of recurrent infection at the time of the last follow-up. Fifteen patients were ambulating without any support whereas 6 patients needed walker support and 2 patients needed a stick to mobilize. Functionally, patients scored a mean HHS of $77.9(68-86)$ and a mean MSTS of $20.0(16-24)$ at their last follow-up. On radiographic assessment, there was no evidence of any radiolucent lines seen at the bone-prosthesis junction on both the AP and lateral views during the latest followup (Fig. 2, Fig. 3 \& Fig. 4). The endosteal collar showed solid osteointegration with the parent bone. No evidence of loosening was seen in any of the radiographs nor did any of the patients have thigh pain on weight-bearing or deep palpation. 
Table 1

Table showing patient details with etiology, anaesthesia grade and functional scores during follow-up

\begin{tabular}{|c|c|c|c|c|c|c|c|c|c|c|}
\hline S.No & $\begin{array}{l}\text { Age } \\
\text { (in } \\
\text { years) }\end{array}$ & Sex & Etiology & $\begin{array}{l}\text { ASA } \\
\text { Grade }\end{array}$ & Complications & $\begin{array}{l}\text { Follow } \\
\text { Up (in } \\
\text { months) }\end{array}$ & $\begin{array}{l}\text { Assistance } \\
\text { while } \\
\text { walking }\end{array}$ & HHS & MSTS & $\begin{array}{l}\text { Presence of } \\
\text { Radiolucent } \\
\text { lines at BPJ }\end{array}$ \\
\hline 1 & 73 & Male & Oncology & II & Nil & 33 & Stick & 81 & 19 & No \\
\hline 2 & 84 & Female & Oncology & III & $\begin{array}{l}\text { Superficial } \\
\text { Wound } \\
\text { Infection }\end{array}$ & 29 & None & 84 & 20 & No \\
\hline 3 & 76 & Male & $\begin{array}{l}\text { Revision } \\
\text { TJR }\end{array}$ & II & Nil & 25 & None & 78 & 21 & No \\
\hline 4 & 67 & Male & $\begin{array}{l}\text { Revision } \\
\text { TJR }\end{array}$ & II & Deep Infection & 30 & None & 72 & 22 & No \\
\hline 5 & 75 & Female & Oncology & II & Nil & 34 & Stick & 86 & 23 & No \\
\hline 6 & 69 & Male & $\begin{array}{l}\text { Non- } \\
\text { Union }\end{array}$ & I & Nil & 22 & None & 75 & 20 & No \\
\hline 7 & 75 & Male & $\begin{array}{l}\text { Revision } \\
\text { TJR }\end{array}$ & II & $\begin{array}{l}\text { Superficial } \\
\text { Wound } \\
\text { Infection }\end{array}$ & 22 & None & 82 & 24 & No \\
\hline 8 & 62 & Female & Oncology & III & Nil & 17 & None & 82 & 21 & No \\
\hline 9 & 50 & Female & $\begin{array}{l}\text { Non- } \\
\text { Union }\end{array}$ & II & $\begin{array}{l}\text { Post- } \\
\text { Operative } \\
\text { Death }\end{array}$ & Nil & Nil & Nil & Nil & $\begin{array}{l}\text { Could not } \\
\text { be } \\
\text { assessed }\end{array}$ \\
\hline 10 & 56 & Male & $\begin{array}{l}\text { Revision } \\
\text { TJR }\end{array}$ & I & Nil & 24 & None & 78 & 18 & No \\
\hline 11 & 80 & Male & $\begin{array}{l}\text { Revision } \\
\text { TJR }\end{array}$ & III & Nil & 22 & None & 76 & 20 & No \\
\hline 12 & 72 & Female & Oncology & III & Nil & 34 & Walker & 64 & 16 & No \\
\hline 13 & 64 & Female & $\begin{array}{l}\text { Revision } \\
\text { TJR }\end{array}$ & II & Nil & 22 & None & 80 & 19 & No \\
\hline 14 & 74 & Male & $\begin{array}{l}\text { Revision } \\
\text { TJR }\end{array}$ & II & Nil & 19 & None & 80 & 22 & No \\
\hline 15 & 77 & Female & Oncology & III & Nil & 22 & Walker & 82 & 18 & No \\
\hline 16 & 81 & Male & $\begin{array}{l}\text { Non- } \\
\text { Union }\end{array}$ & II & Nil & 21 & None & 76 & 18 & No \\
\hline 17 & 59 & Female & Oncology & III & Nil & 24 & None & 82 & 21 & No \\
\hline 18 & 51 & Female & $\begin{array}{l}\text { Revision } \\
\text { TJR }\end{array}$ & II & Deep Infection & 19 & Walker & 70 & 19 & No \\
\hline 19 & 69 & Male & $\begin{array}{l}\text { Revision } \\
\text { TJR }\end{array}$ & III & Nil & 16 & None & 84 & 22 & No \\
\hline 20 & 57 & Male & $\begin{array}{l}\text { Revision } \\
\text { TJR }\end{array}$ & III & Nil & 25 & None & 82 & 22 & No \\
\hline 21 & 72 & Female & $\begin{array}{l}\text { Revision } \\
\text { TJR }\end{array}$ & III & Nil & 26 & Walker & 78 & 20 & No \\
\hline
\end{tabular}

ASA-American Society of Anaesthesiology; HHS - Harris Hip Score; MSTS - Musculoskeletal Tumor society Score; BPJ Bone-prosthesis junction 


\begin{tabular}{|c|c|c|c|c|c|c|c|c|c|c|}
\hline S.No & $\begin{array}{l}\text { Age } \\
\text { (in } \\
\text { years) }\end{array}$ & Sex & Etiology & $\begin{array}{l}\text { ASA } \\
\text { Grade }\end{array}$ & Complications & $\begin{array}{l}\text { Follow } \\
\text { Up (in } \\
\text { months) }\end{array}$ & $\begin{array}{l}\text { Assistance } \\
\text { while } \\
\text { walking }\end{array}$ & HHS & MSTS & $\begin{array}{l}\text { Presence of } \\
\text { Radiolucent } \\
\text { lines at BPJ }\end{array}$ \\
\hline 22 & 81 & Male & Oncology & III & $\begin{array}{l}\text { Death after } 18 \\
\text { months } \\
\text { related to } \\
\text { metastasis }\end{array}$ & 16 & Walker & 72 & 19 & No \\
\hline 23 & 69 & Female & $\begin{array}{l}\text { Revision } \\
\text { TJR }\end{array}$ & III & Nil & 28 & None & 68 & 16 & No \\
\hline 24 & 54 & Male & Oncology & II & Nil & 22 & Walker & 80 & 22 & No \\
\hline
\end{tabular}

\section{Discussion:}

The main finding of our study was that Pantheon PFR prosthesis showed good clinical and functional outcomes in the short term with no case showing evidence of loosening and no cases requiring revision.

Over the years PFR has emerged as a useful option in both young and elderly patients for various aetiologies. Young patients, mostly after oncological resection, have high demand and an increased life expectancy and hence implants with increased longevity are necessary. Likewise in elderly patients, following PFR a further revision surgery may not be feasible due to increased morbidity and mortality associated with the procedure [4]. Hence, achieving osseointegration at the bone-prosthesis junction and thereby preventing the cascade of loosening is vital. The porous endosteal titanium bridging collar was designed at aiming to achieve ingrowth, prevent loosening, and thereby ensuring better outcomes. Our early results do not show evidence of loosening and this is re-assuring. Longer follow-ups of these patients are essential to monitoring for osteointegration.

Modular endoprostheses have showed increased implant longevity and better functional outcomes for both oncological and non-neoplastic conditions [13-15]. Chandrasekar et al. in their analysis of results of 100 consecutive modular endoprosthesis, METS (Stanmore Implants Worldwide), showed a 5-year implant survival of $90.7 \%$ and a mean Toronto Extremity Salvage Score of $61 \%$ [13]. Sewell et al. reported that of 15 patients who underwent modular PFE for non-neoplastic conditions there was a prosthesis survival of $87 \%$ at 5 years and a mean HHS of 70 at the final follow-up [14]. Our results also indicate that modular PFE is associated with favorable results both with implant functional and clinical outcomes.

Numerous designs and advances in technology have been made to achieve better osseointegration of prosthesis to the bone. Good integration at the bone-prosthesis junction reduces aseptic loosening by preserving load transfer at the shoulder of the implant [16] as shown by Chao and Sim. To facilitate good integration, the material used and the coating becomes important. Porous coating implants have been shown to demonstrate accelerated bone ingrowth in animal models [17] and the same concept has been implemented in prosthesis designs for humans [18] however, studies on retrieved implants with these surface coatings often show limited or no osteointegration [19]. In primary distal femoral replacement, a hydroxyapatite-coated collar can lead to significantly reduced loosening of those implants that were identified to have osteointegration on radiographs [20] however only $60 \%$ of the implants were osseointegrated. To combat this low incidence of integration, laser sintered porous collars have been designed and in animal studies, osteointegration has been shown throughout the porous structure [9]. Titanium alloys have been shown to have excellent mechanical properties including high specific strength and biocompatibility to mimic bone. The prosthesis we used was based on these principles and showed good promising early results with no evidence of radiolucent lines suggestive of loosening.

PFR surgeries are uncommon and only done in a few centers. Hence, there is a relative paucity of studies reporting outcomes for PFR. While HA-coated collars have been studied and reported, there are few studies reporting outcomes of porous titanium bridging collars in PFR. Our study analyzing the functional and radiological outcomes of this novel prosthesis is the central strength of the study. Our promising results would encourage surgeons to use this prosthesis in PFR surgery. 


\section{Limitations of our study}

Our study is not without limitations. Short follow-up, retrospective nature of the study, and single-center results are important limitations of our study. Retrospective studies always have the inherent risk of variability in data collection but however, we carefully scrutinized the patient data and collected all details. These are results only from a single-center, however, surgeries involving PFR happen only in few tertiary centers in the hands of experienced surgeons thus, even if a multi-centric study analyzing the cases from all other centers was performed the number of cases per annum would still be expected to below. We intend to follow-up on these cases and analyze the long-term results of these patients. The rarity of PFR surgeries performed makes it difficult to establish cohorts and compare results among them due to the low numbers. We also intend to perform a multi-center study involving centers that have used this prosthesis and increased numbers would help us overcome this limitation and would enable outcome analysis cohorts based on etiology.

Our short-term results demonstrate good functional outcomes with the integration of the endosteal collar and no evidence of radiographic loosening in a consecutive series of patients. Further studies are required to assess the long-term outcomes seen with this implant.

\section{Conclusion:}

Aseptic loosening remains an important factor, detrimental to good outcomes, following PFR. Our short-term study shows the use of titanium porous endosteal bridging collars in PFR to be promising resulting in reliable osteointegration at the boneprosthesis junction and also allowing good clinical and functional outcomes. Further studies are required to assess the mid to long-term outcome seen with this implant.

\section{Abbreviations}

PFE: Proximal Femoral Endoprosthesis

MSTS: Musculoskeletal Tumor Society

HHS: Harris Hip Score

NICE: National Institute for Health and Clinical Excellence

\section{Declarations}

\section{Ethics approval and consent to participate:}

This Ethics committee of our hospital (OUH Trust) approved this study as an audit project the reference number of approval was 6647

All patients consented for their clinical details and radiographs to be used for this study

\section{Consent for publication:}

All patients gave their consent for their details to be used anonymously and gave their consent for publication

\section{Data Availability statement:}

No linked research data is available with this submission. For readers who want to access the data, they can write to the authors and then the data will be made available on request.

\section{Competing Interests:}

The authors declare the following competing interests 
The author or one or more of the authors have received or will receive benefits for personal or professional use from Adler Ortho Spa. However, this has no direct or indirect relation to the subject of this article.

\section{Funding Statement:}

No funding was received for this study

\section{Author Contributions:}

- RBR: Conception of the study, tabulation and interpretation of data, writing of manuscript

- TWH: Writing of manuscript

- DW, BK, AT \& TC: Conception of the study, suggested corrections in manuscript, final approval of manuscript for submission

- CG: Suggested corrections in manuscript, final approval of manuscript

- GB: Writing of manuscript, final approval of manuscript for submission

\section{Acknowledgements:}

RBR is a Girdlestone Scholar at the Oxford University whose scholarship has been funded by the Lord Nuffield Orthopaedic Centre Trust

\section{References}

1. Khajuria A, Ward J, Cooper G, Stevenson J, Parry M, Jeys L. Is endoprosthetic replacement of the proximal femur appropriate in the comorbid patient? Hip Int. 2018 Jan;28(1):68-73. doi: 10.5301/hipint.5000520. PubMed PMID: 29048688.

2. Grammatopoulos G, Alvand A, Martin H, Whitwell D, Taylor A, Gibbons CL. Five-year outcome of proximal femoral endoprosthetic arthroplasty for non-tumour indications. Bone Joint J. 2016 Nov;98-B(11):1463-1470.

3. Parvizi J, Tarity TD, Slenker N, Wade F, Trappler R, Hozack WJ, Sim FH. Proximal femoral replacement in patients with nonneoplastic conditions. J Bone Joint Surg Am. 2007 May;89(5):1036-43. PubMed PMID: 17473141.

4. Coathup MJ, Sanghrajka A, Aston WJ, Gikas PD, Pollock RC, Cannon SR, Skinner JA, Briggs TW, Blunn GW. Hydroxyapatitecoated collars reduce radiolucent line progression in cemented distal femoral bone tumor implants. Clin Orthop Relat Res. 2015 Apr;473(4):1505-14. Doi 10.1007/s11999-014-4116-6. Epub 2015 Jan 30. PubMed PMID: 25634027; PubMed Central PMCID: PMC4353558.

5. Blunn GW, Briggs TW, Cannon SR, Walker PS, Unwin PS, Culligan S, Cobb JP. Cementless fixation for primary segmental bone tumor endoprostheses. Clin Orthop Relat Res. 2000;372:223-230.

6. Bergin PF, Noveau JB, Jelinek JS, Henshaw RM. Aseptic loosening rates in distal femoral endoprostheses: does stem size matter? Clin Orthop Relat Res. 2012 Mar;470(3):743-50. doi: 10.1007/s11999-011-2081-x. PubMed PMID: 21968899; PubMed Central PMCID: PMC3270169.

7. Wirganowicz PZ, Eckardt JJ, Dorey FJ, Eilber FR, Kabo JM. Etiology and results of tumor endoprosthesis revision surgery in 64 patients. Clin Orthop Relat Res. 1999 Jan;(358):64-74. PubMed PMID: 9973977.

8. Ward WG, Johnston KS, Dorey FJ, Eckardt JJ. Loosening of massive proximal femoral cemented endoprostheses. Radiographic evidence of loosening mechanism. J Arthroplasty. 1997 Oct;12(7):741-50. PubMed PMID: 9355003.

9. Mumith A, Coathup M, Chimutengwende-Gordon M, Aston W, Briggs T, Blunn G. Augmenting the osseointegration of endoprostheses using laser-sintered porous collars: an in vivo study. Bone Joint J. 2017 Feb;99-B(2):276-282. doi: 10.1302/0301-620X.99B2.BJJ-2016-0584.R1. PubMed PMID: 28148673.

10. Herrera A, Mateo J, Gil-Albarova J, Lobo-Escolar A, Ibarz E, Gabarre S, Más Y, Gracia L. Cementless hydroxyapatite coated hip prostheses. Biomed Res Int. 2015;2015:386461. doi: 10.1155/2015/386461. Epub 2015 Feb 23. PubMed PMID: 25802848; PubMed Central PMCID: PMC4352755. 
11. Blunn GW, Wait ME. Remodelling of bone around intramedullary stems in growing patients. J Orthop Res. 1991 Nov;9(6):809-19. PubMed PMID: 1919843.

12. Chao EY, Sim FH. Composite fixation of segmental bone/joint defect replacement(SDR) prostheses. Biological and biomechanical justifications. Chir Organi Mov.1990;75(1 Suppl):171-3. PubMed PMID: 2249522.

13. Chandrasekar CR, Grimer RJ, Carter SR, Tillman RM, Abudu A, Buckley L. Modular endoprosthetic replacement for tumours of the proximal femur. J Bone Joint Surg Br. 2009 Jan;91(1):108 - 12. doi: 10.1302/0301-620X.91B1.20448.PubMed PMID: 19092014.

14. Sewell MD, Hanna SA, Carrington RW, Pollock RC, Skinner JA, Cannon SR, Briggs TW. Modular proximal femoral replacement in salvage hip surgery for non-neoplastic conditions. Acta Orthop Belg. 2010 Aug;76(4):493-502. PubMed PMID: 20973356.

15. Rajasekaran RB, Palanisami DR, Natesan R, Jayaramaraju D, Rajasekaran S. Megaprosthesis in distal femur nonunions in elderly patients-experience from twenty four cases. Int Orthop. 2020 Apr;44(4):677-684. doi: 10.1007/s00264-019-04383-1. Epub 2019 Aug 7. PMID: 31392494; PMCID: PMC7224092.

16. Chao EY, Sim FH. Composite fixation of salvage prostheses for the hip and knee. Clin Orthop Relat Res. 1992 Mar;(276):91101. PubMed PMID:1537180.

17. Dabrowski B, Swieszkowski W, Godlinski D, Kurzydlowski KJ. Highly porous titanium scaffolds for orthopaedic applications. J Biomed Mater Res B Appl Biomater. 2010 Oct;95(1):53-61. doi: 10.1002/jbm.b.31682. PubMed PMID: 20690174.

18. Ryan G, Pandit A, Apatsidis DP. Fabrication methods of porous metals for use in orthopaedic applications. Biomaterials. 2006 May;27(13):2651-70. Epub 2006 Jan 19. Review. PubMed PMID: 16423390.

19. Tanzer M, Turcotte R, Harvey E, Bobyn JD. Extracortical bone bridging in tumor endoprostheses. Radiographic and histologic analysis. J Bone Joint Surg Am. 2003 Dec;85(12):2365-70.

20. Coathup MJ, Batta V, Pollock RC, Aston WJ, Cannon SR, Skinner JA, Briggs TW, Unwin PS, Blunn GW. Long-term survival of cemented distal femoral endoprostheses with a hydroxyapatite-coated collar: a histological study and a radiographic follow-up. J Bone Joint Surg Am. 2013 Sep 4;95(17):1569-75.

\section{Figures}




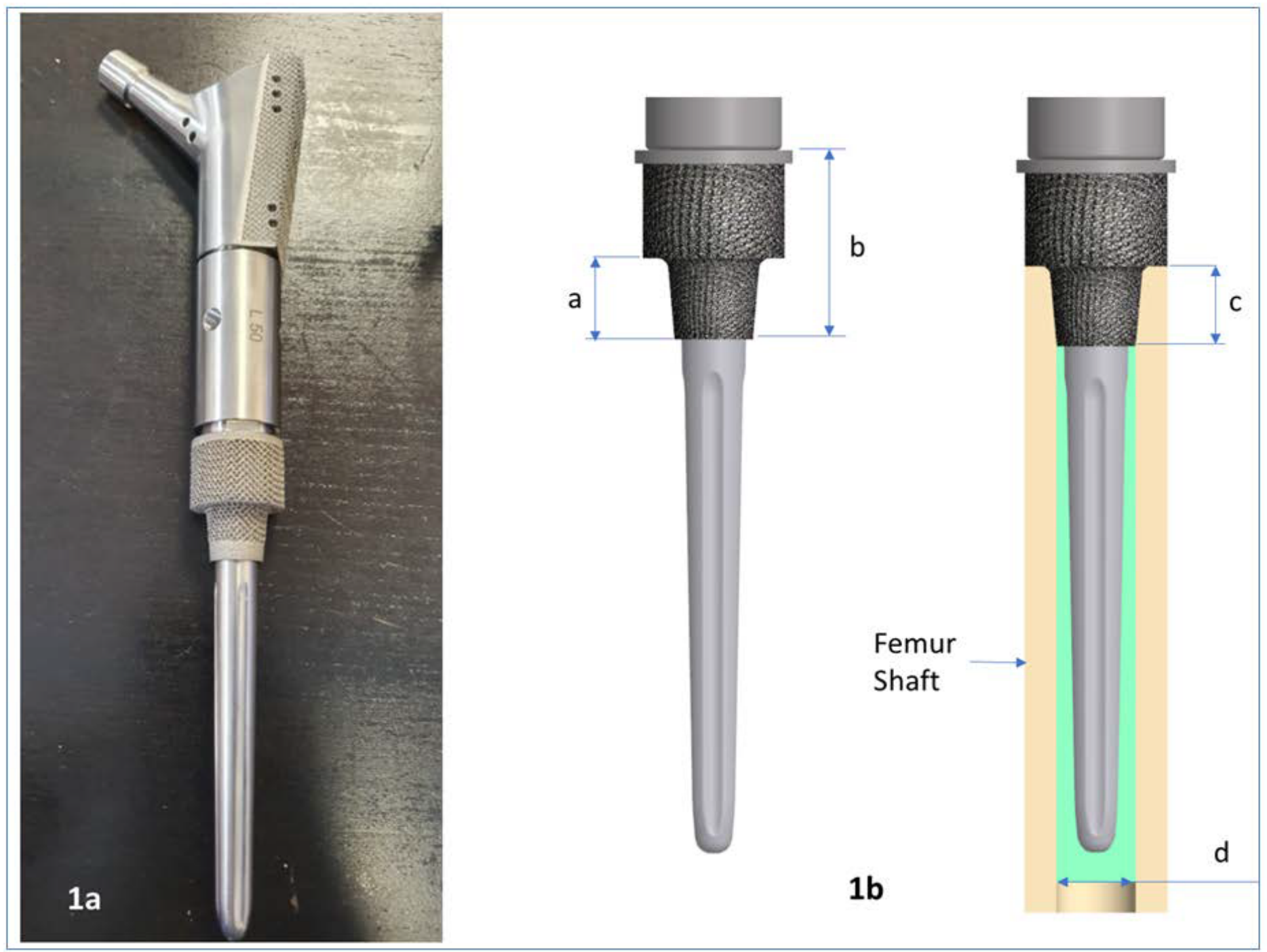

\section{Figure 1}

a showing the Pantheon PFR Implant; b - Diagrammatic representation showing the Implantation technique of the prosthesis in the femur. a- showing endosteal part of bridging collar, b- showing entire bridging collar, $\mathrm{c}-$ No cement between the collar and the bone when inserted into the femur shaft, $d$ - showing the cement stopper 


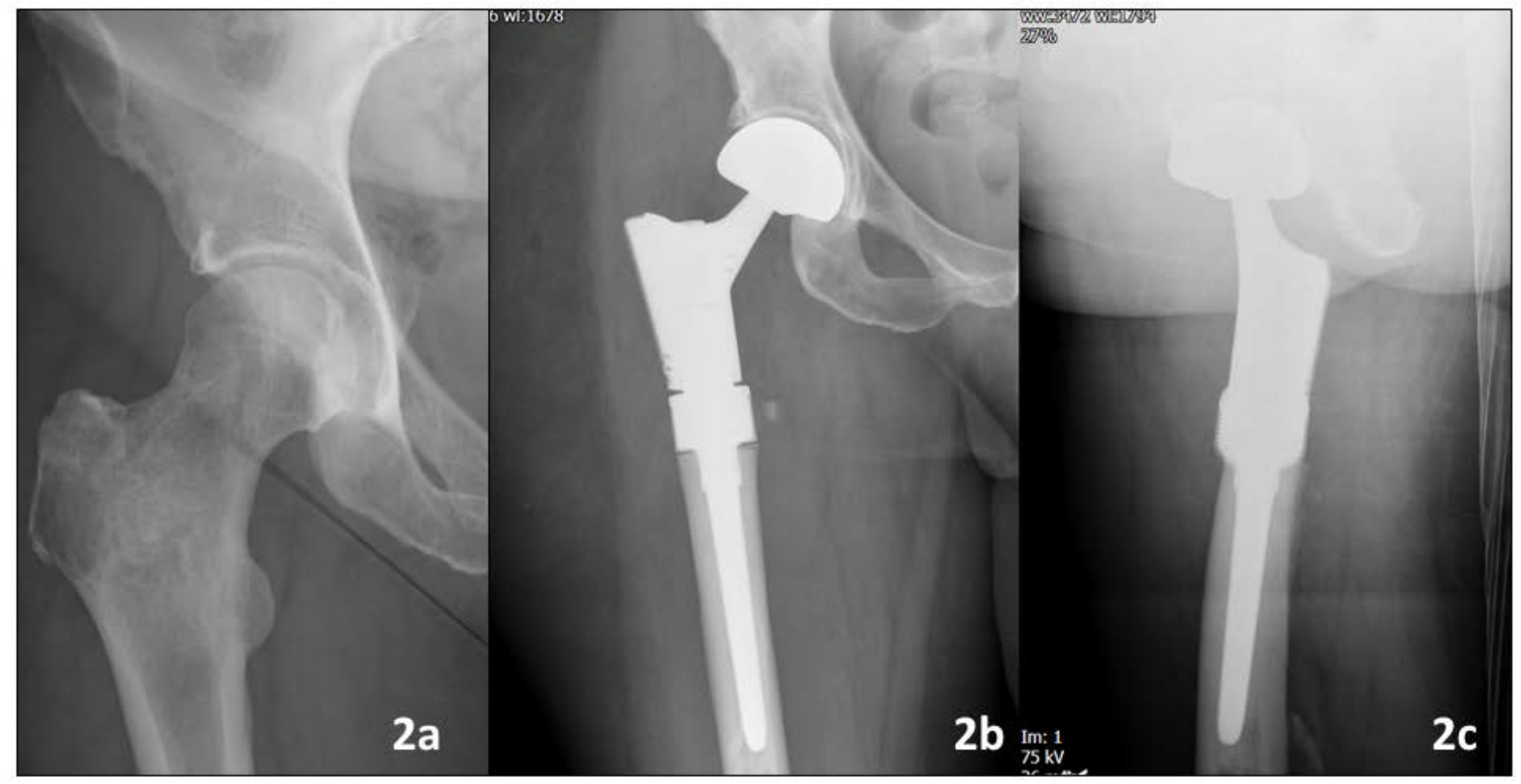

\section{Figure 2}

Patient with isolated metastatic lesion in the right proximal femur (2a) managed with excision and prosthesis replacement. Radiograph at 15 month follow-up showing no evidence of loosening ( $2 b \& 2 c)$. 


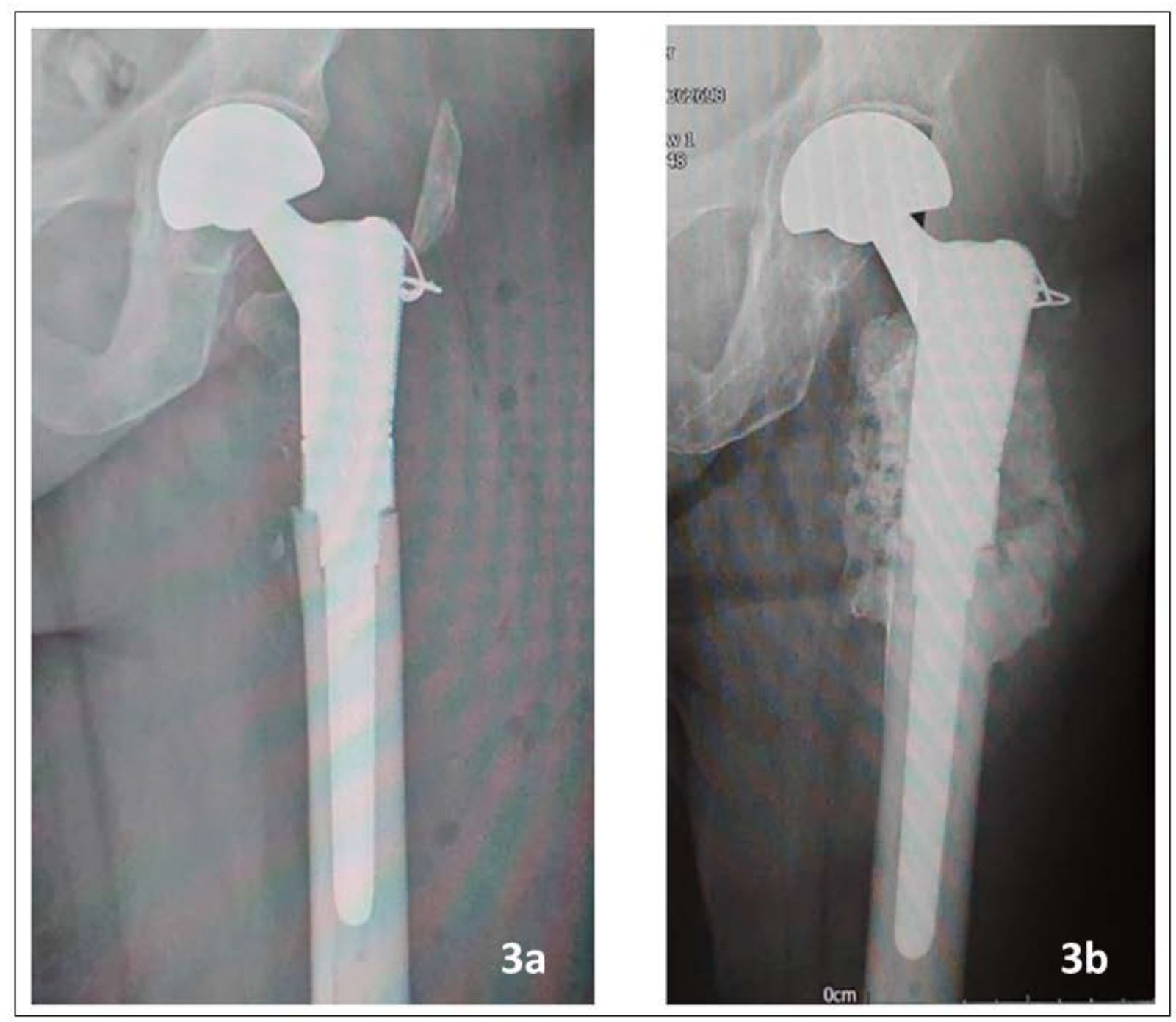

\section{Figure 3}

Immediate post-op radiograph (a) and radiograph after 2 years showing good integration of the prosthesis and the collar and bony integration over the implant surface. Minimal heterotrophic ossification is seen at the implant-bone interface. The patient is doing clinically well with HHS score of 84 and MSTS score of 20 at latest follow-up. 


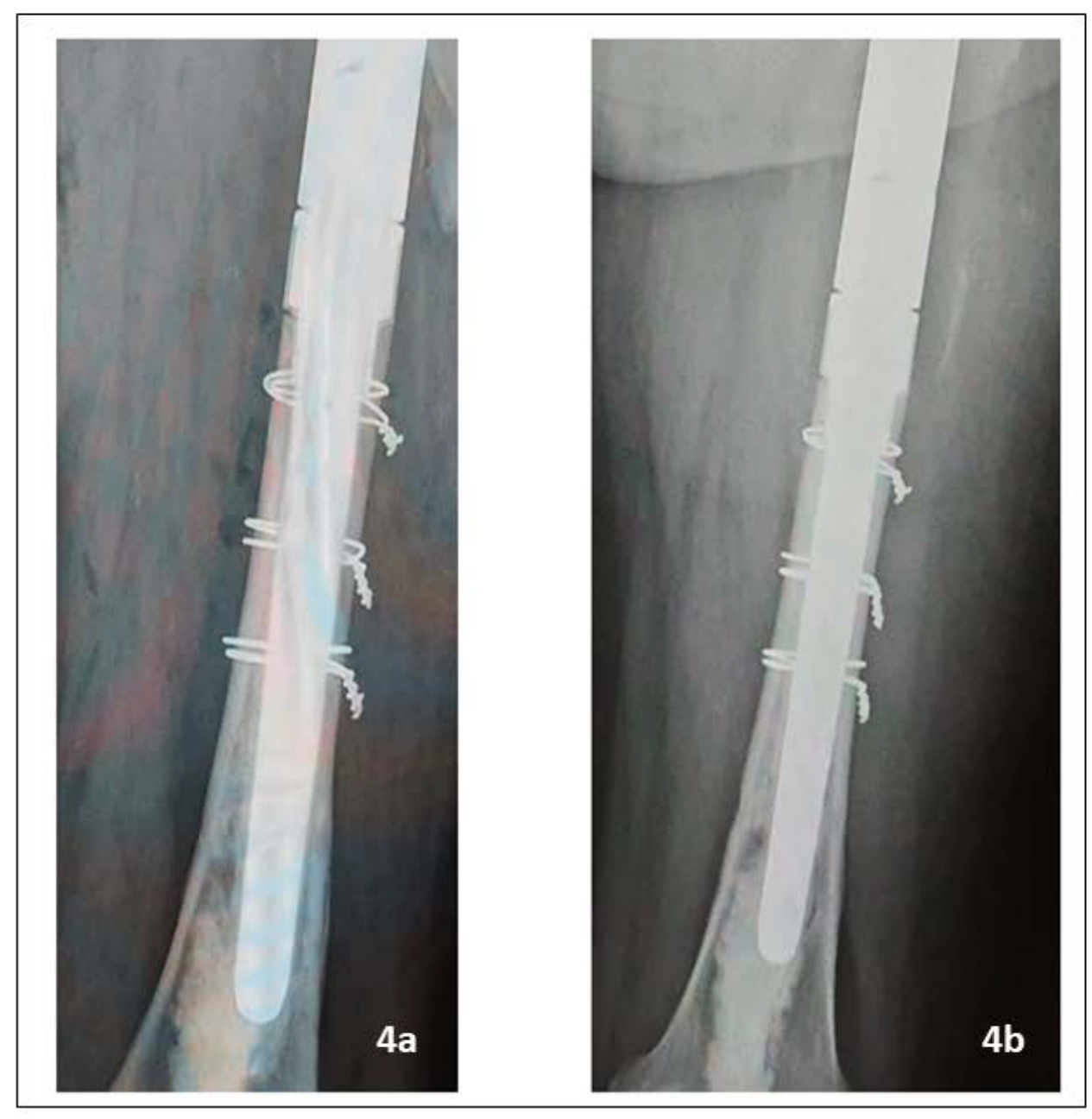

\section{Figure 4}

Immediate post-op Radiograph (a) and radiograph at 16 months follow-up showing good integration at the bone prosthesis junction and no evidence of radiolucent lines (b) 